\title{
Meeting the calculated market needs for optically trained physicists, engineers, and technicians in 2005
}

\author{
Robert Breault
}

Robert P. Breault, "Meeting the calculated market needs for optically trained physicists, engineers, and technicians in 2005," Proc. SPIE 3190, Fifth International Topical Meeting on Education and Training in Optics, (8 December 1997); doi: 10.1117/12.294363

Event: Fifth International Topical Meeting on Education and Training in Optics, 1997, Delft, Netherlands 
Meeting the calculated market needs for optically
trained physicists, engineers, and technicians in 2005

Robert Breault

Breault Research Organization, Inc

Arizona Optics Industry Association

Tucson, Arizona 85715

520-721-0500 Off

520-721-9630 Fax

bbreault@breault.com

\begin{abstract}
This paper addresses a not-too-distant need for many more optically trained personnel, far more than the current system can supply. The field of photonics and optics is quickly maturing in a very natural evolutionary manner. However few people, maybe none, fully recognize and appreciate the current evolutionary state of its markets, their size, and the state of manpower preparation, or the lack thereof, of the associated industry. Nor are the threats that this positive growth poses being recognized. Some enlightened countries have their sights on specific sectors of the industry and are investing heavily, some are just entering with great expectations, and other countries are just not in the chase. However, few national programs have come to the realization that there will not be enough trained personnel to meet the market demand.
\end{abstract}

Optics, photonics, education

\title{
KEYWORD LIST
}

\section{INTRODUCTION}

This talk takes on a considerably different spin than most of the sessions addressed at this conference. It is about money, massive amounts of money, trillions of dollars per year! While that may be a turnoff to some, no offense is intended. My fundamental theme is a cry to support every presenter, educator, business, and public sector individual who has taken some time to support and promote the technology. We need more promoters of technical optics; more teachers of optics, and new methods of teaching optics for people whose love is directed into other disciplines and other industries, other industries that are now in ever growing need for "some" optical design and analysis ability. This includes the automobile, lighting, agriculture, medical, and manufacturing industries to mention a few. It is about a challenge, one that the academic community, to some degree, has accepted and embraced already, more so than my industry peer group has. This conference is an acknowledgment that the academic optics community has recognized to some degree the need to increase the pool of educated optics professionals, and is trying to do something about it.

But to meet the projected market need a good proportion of the optics graduates need to be encouraged to learn about and master wholly different areas of knowledge, such as sales, marketing, Venture Capital, and conflict negotiation. They must also be multi-lingual, facile on the Web, the Internet, Video teleconferencing, export trade issues, IPOs, ESOPs, trusts, insurance, mergers, joint ventures, partnerships, distributors, consolidation, compensation, Angels, debt and equity financing, entrepreneurship, risk taking, market driven, technology driven, the industrial prototype, exit strategies, planning for the IPO, C Corp, S-Corp, LLC, International Accounting firms, letters of credit, and more. It sounds like an MBA with experience, doesn't it. To many, technology and MBA are not personally appealing. To some of you, it is no way your job in life and has no effect on you. Wrong! At least on the latter issue. 


\section{THE PROBLEM! WHAT'S DIFFERENT? SNELL'S LAW IS NO LONGER TRUE!}

Nothing seems to work like it used to.

Just contemplate for a moment the ramification of the impact of changing just one fundamental law of optics on the world we see. In a very real sense the rules/laws of the world economies have undergone such a radical change. And just like a scientist, economists are fast on the track to figure out what the new "Snell's Law" is, and the business community today is groping with "What's happened". Nothing seems to work like it used to. Industries in general have gone through a dramatic discontinuous change in this decade: "The Wall" came down, essentially simultaneously as the Internet, and Web came up, and the world dove into global marketing like it never has before. The aerospace/defense industries downsizing has affected just about all of the industry and a lot of our intended research. There is little similarity in today's market, its manufacturing capability, its mobility of money and knowledge, and the general intelligence and savvy of the business community in any corner of the globe. All can be moved into action in very short periods of time. To the global businessman the rules of the game are different. Add to that a special concern for the optics industry, and it appears the forecasters are predicting a boom time in general for the next eight years, and hyper growth in the optics industry. We are not ready for it. There has been too much happening, too fast, without any clear time to contemplate, discuss, and plan for it.

Some portions of this current boom were predicted by Charles Handy in his "Age of Unreason" in 1989, when he predicted the globalization and mobility of information and people, and the need to employ, or re-employ, the world's reserve of intellectual workers: early retirees, housewives, etc., because the Baby Boomers would reach their prime spending years in 1995 and keep spending for the next eight years. If it wasn't the optics industry another phenomenon would probably been predicted, and could have been. But our infant industry missed predicting this "phenomenon".

Very often when there is a new technology breakthrough there is typically a fury of energy, attention, and people directed towards the future possibility of this technology. For many academics and research scientist this is a way of life. They are driven to be the next person to be the first to discover some new aspect of this revolutionary field. They get "with it", do in-depth research, publish papers, take on graduate students, do consulting, and all play a role in creating prototype revolutionary new instruments. A mature industry on its behalf invests heavily in research and facilities in anticipation of a calculable future market. We have all seen this, and many of us in optics have played a prominent role in some aspect of this. Exactly what is it that a more mature industry would have recognized and predicted? In the world of economics, some work has pointed out that revolutionary technology takes about 20 years to do the break through technology development, live through all the pipe dreams of what the field is going to accomplish with far more optimistic delivery schedules than are realized. Then it enters into the next 20 years of underestimated growth and commercialization of the industry. What about our industry? Lasers came out in the late 60's as research tools, more so in the early 70's. Fiber optics was developed in the 70's. How many people then had the vision about what commercial value lasers would get into? Very few of those initially involved in the fiber optics industry, one of the exceptions was the Corning Glass family, had a clear vision of where fiber optics could go. The same goes for all sectors of our industry.

The current estimated size of the global market for just the photonics industry is about $\$ 50$ million, growing to $\$ 500$ million by the year 2010. I sense that that is under- estimated and conservative, just like industry has underestimated the personal computer industry size and growth, and we have underestimated the laser and fiber market industries to name a few. How much higher this number will be is only a guess at this time. We are talking about a growth factor of 10 or more in the next twelve years. If one assumes it takes an average of about five years to get a Ph.D. and then a few years to establish oneself, we are faced with the problem that there are not enough students in the system to support the growth. . We are going to have to solve the "problem" differently. And by "we" I am putting the challenge to the business and academics to play a major role in economic development. We have a poor track record at being an active participant in the past. In many cases the expression that could be used is "it is not my job, nor my desire to be involved". We have been apathetic in our response to the growth of our own industry.

I presume, rightly or wrongly, that most of the people at this conference are academically and academicians who are mostly education oriented, at least some of whom are happy to be "away" from politics and the realities of business. This message is for the all who are involved in photonics and optics. Note that I did not limit that to the 
industrial sector. I cite that because I am presenting a businessman's view of the short and long term needs of the photonics and optics industries, and to point out that to some real degree Industries are from Mars and Educators are from Venus. This in no way values one more than the other, nor do I wish to create a chasm. The two are very different in several important ways.

- To industry, all technical information is proprietary.

- All contacts are company sensitive.

- Industry does not converse openly about their technology with their competition.

- Educators on the other hand in many cases must publish or perish.

- Educators communicate with their peers around the world.

- One sector needs to drive the technology to refinement and perfection for commercial purposes, the other tends to be the first to show a thing can be done and then goes onto a different project once the funding ends.

- Researcher are often in the hunt for new sources of revenue, and are often "motivated" by survival to move onto the next topic before the commercialization of their technology has been realized.

- The industries are heavily regulated at the company, national and even international level, while academics publish the same information, and, in fact, are encouraged to in most cases, when the industrialists would face fines and subpoenas.

This problem is not an academic one, my purpose is to impress upon all sectors of our community that we have turned a corner in our industry. We have gone beyond break through technology development, soared through the aerospace defense industries, and parachuted into the commercial world as the defense industries around the world downsized. Parachuted because it surely has been a savior to many of our industrial members. To me it is with considerable embarrassment that we, as the business, economic, and academic sectors, have utterly failed as a group to realize that we had grown up. In some ways we are still acting like the college undergraduate; fun, thrills, and joy rides. Meanwhile we all had developed some substantial technology that could have and should have serviced a far broader sector of the commercial markets than we even now imagine, let alone service.

The science and physics of light, as we all recognize, is an $E^{3}$ technology; it services Emerging technologies, Enhances existing technologies, and helps Existing technologies evolve. The problem is here now! Industry is "constantly calling Arizona, Connecticut, Florida, and Georgia optics institutions for trained people. "If graduates are not available now, who will be soon?" Each student is getting multiple offers. You can say what a difference three years makes, but then again there where those who predicted it would be like this. Most of us probably did not hear them. Certainly we have not addressed the issue sufficiently. Massachusetts, Arizona, and Northern California have a need for many more optics trained people now! If your first reaction is that the problem will solve itself, industry and schools will respond, my reply is it is in fact too late already. We did not respond in time. This conference will address some of the needs. It is a very important part. But there are many parts, and like any good symphony, all the players need to be informed and in tune.

\section{THE NEED}

We need to inspire young people at all ages to consider the field of Technical Optics. We need more teachers of optics, and new methods of teaching optics to people whose love of engineering is directed into other disciplines, other industries, that are now an ever growing need for "some" optical design and analysis ability. Several other papers at this conference address additional "other" industries.

We are an "Old" industry, yet we are one of the youngest: Young in new technology, Young and inexperienced in business leadership skills. In a way we all are novices in our profession. Our teachers have done well, but it is time to move the milepost out further as a goal. We all need to support our school systems at all levels to encourage our teachers to teach their pupils more than to do breakthrough science; to do more than teach them to be employable. Teach them to be employers. Promote the creation of jobs, and encourage entrepreneurism.

As for education we are preaching to the converted. We need to identify our stake holders, strategies, and what our vital cycle is, who is in it, and how to put it to work. A Vital Cycle in this case is the combination of the 
"educational system" and its supporting foundations that are crucial to its health and whose own health depends on the success of the educational efforts. For instance, industry, quality of life, telecommunications, government, and publishers. Each in their own way could help improve the delivery system and in return get stronger. In concept, every part of a vital cycle is dependent upon it, and both helps and benefits from the cycle's efforts. Where is the business community at now? In the office coping with making money. Why aren't they with it? Why aren't they here? Where are our community leaders? Asleep at the wheel? Why aren't they with it? Why aren't they here? We need to engage the entire community. Education is now, more than ever, everybody's business.

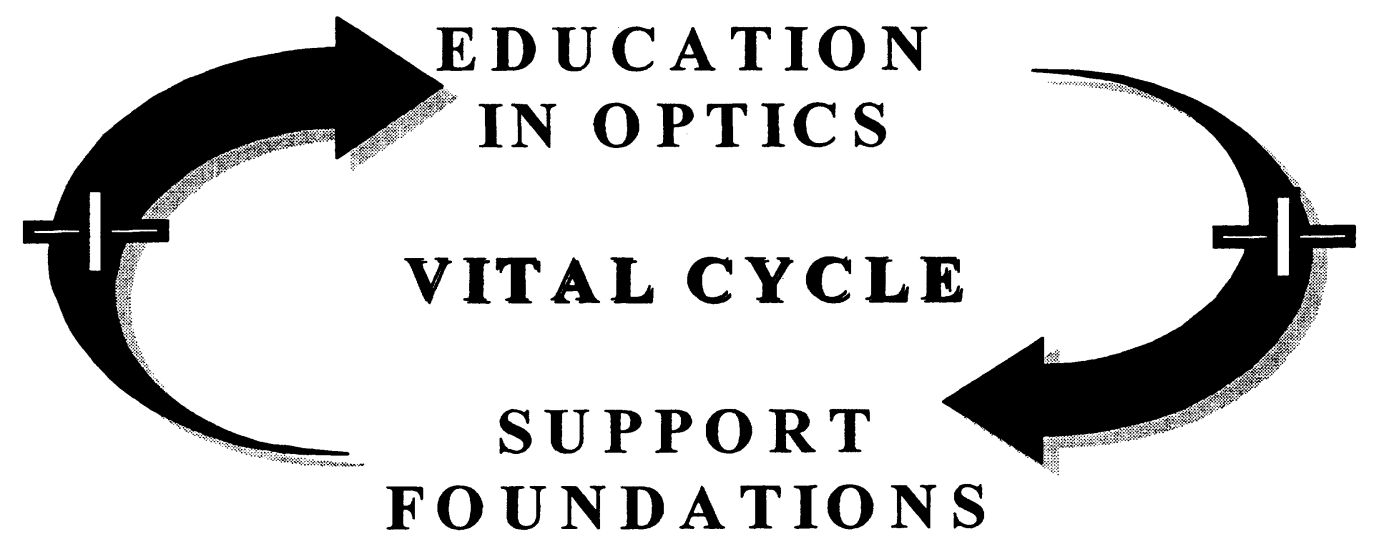

\section{Objectives}

The objectives should be clear. To gather all the stakeholders in the global community and create a multi-faceted plan to deliver the needed trained resource to the community. Think and teach the technical sciences but also entrepreneurship, business acumen, and promote the selection of theses and dissertations that do both. When in a growth "crisis" the businessman needs to be creative. The successful business needs to gather up all the willing and useful resources in all countries and partner with them, plan with them, divide the gold with them, and take the market by storm.

\section{Obstacles to implementation \\ "It can't be done", or "We tried it"}

I for one won't listen to "It can't be done", or "We tried it". That does not mean that I don't recognize that there are many obstacles to implementation. Governments will get in the way. However unintentional their action may be, they do get in the way to the benefit of very few. There will be turf wars between industry and academic institutions about Intellectual Property Rights, patent rights, and academics doing industry research projects. Forming the executive team of business leaders, academics, and public sector champions will be a challenge. What is in it for "them" now? Who will lead it? Business or academics? How will it be sustained? The optics community is currently too short-sighted to readily embrace this concept. We need to market the idea and find the champions. Once it is in place, we can count on someone to abuse the system. If there is going to be certification who will administer the certification? Will it be a global certification? If not, then why not? Who will fund it? All the stake holders!

\section{Structure}

We need a coordinated plan for the $21^{\text {st }}$ century.

We need a coordinated plan for the $21^{\text {st }}$ century, or as some like to say, "the Age of Enlightenment". I think that it is safe to assume that we each love our science and love doing it. I suggest a global effort be made between the academics, the industrials, and the public sector, yes across borders, to develop a strategy to promote careers in the field of optics at all levels of education, promote the opportunities of such careers, create a "standard", a certification of various levels of accomplishment. We need to educate our public sector as to the economic 
opportunities of our industry, and support surveys and market analysis of our industry so that investors of all sorts can find market data in our field. Today it does not exist. Today it takes yet another leap of faith by the investors to invest in some new technology in our field. There is more than enough to go around, $\$ 500$ billion dollars. We should create a global awareness of the current market size and products used daily that require optics. Make the world more aware of the industry and its future size, so that investors will put more money into the technology, and governments will support Research and Development and education. Educate our communities that we are not just perceived as being only about eye glasses and telescopes. Educate our teachers, legislators at all levels.

I suggest a global effort be made between the academics, the industrials, students, the optics related societies, the members and participants of Coalition for Photonics and Optics (CPO), the International Commission for Optics (ICO), and the public sector of multiple nations, yes across borders, to develop a strategy to:

- promote careers in the field of optics at all levels of education,

- promote the opportunities of such careers,

- create a "standard", a certification of various levels of accomplishment,

- educate our public sector as to the economic opportunities of our industry, and for

- encourage industries to support surveys and market analyses of our industry so that investors of all sorts can find market data in our field. Today it does not exist.

\section{Action Initiatives, Tasks, Challenges}

The following are some more brief thoughts on initiatives to alleviate the shortage problem even if we can't immediately solve it. The proposal involves just some of the stakeholders. I am sure more will be added as needed or identified. In fact consider the following as just "sound bites" of some possible challenges. Almost any one of them is worthy of a paper in its own right.

\subsection{The challenge for the academic institutions.}

Continue to teach, and listen to new ways to teach, involve industry and listen to its latest technology needs, support issues to inform the public sector, and motivate students. The words "Continue to teach" is in italics because I am sure that when the money gets bigger and the shortage more severe industry will consume its "seed corn", the professors. They will be enticed by salaries that today would seem unrealistic. That will exacerbate the development of more students with a better education. I have called out that we need to teach more than an optics education. We need to "teach" a technical field without beating the students to "death" with the mathematics, and constant calculations. It has to retain the fun aspect of learning. We cannot afford to burnout as many as we are doing today. Teach students to think beyond learning to find a job. Teach them to make jobs, to be entrepreneurs! Academic institutions need to think regional development and benefit. Use the Stanford method. Do not be too greedy. Holding the technology ransom benefits no one. It will die, industry will find other ways or find improvements that break tightly held patents. Industry could use 2 yr. Associate engineering, and undergraduate degrees. Industry market driven curriculum, customization, needs to be developed. Continuous learning in industry is needed. Technology in general is changing so rapidly industry leaders need to maintain a currency in their field and sister industries. Some portions of our industry would benefit by specialized modular courses. The public and private sectors need to reconcile a sound financial strategy - for research, universities, industries. Finally we desperately need graduates with global cultural awareness, multi-lingual graduates.

\subsection{The challenge for the industrial institutions.}

It is my observation that small and mid-sized companies have not recognized their obligation and important role to actively participate in the motivation and education of students especially in the lower elementary schools. Who else is better at selling the love we have for our field and the opportunities it presents? The partnership involves higher schools of learning; participation in tutorials, shop visits, awards, study grants, internships, and the interface 
with the public sector; yes politics! The smaller and mid-sized companies need to band together to financially support graduate education. They need to design and support tools and kits for teaching optics at all levels. If the educational system is going to create continuous learning in industry programs, industry will need to support them or let institutions know that they are NOT needed beforehand. Industry will need to engineer it differently. If we are not going to have all the MS and Ph.D.s we want, we will have to build in the engineering so that the user will not have to have a Ph.D. in optics to use it. When there are not enough employees to go around we will need to use the resources smarter than we are now. Cooperation, at least co-opetition where we both compete and cooperate, will become the norm. Whenever we don't, we will just leave more of the $\$ 500$ billion on the table. The industry will go under-serviced. Industry will probably gracefully exchange or multi-license its technology - for a fee. For a piece of the $\$ 500$ billion dollars. Industry can turn to additional people resources; retirees; home bound spouses, and the physically challenged. In particular, encourage the development of tools for the visually, and hearing challenged community.

\subsection{The challenge for the public sector.}

The public sector needs to listen, learn, support, and motivate the consortium of industries and groups. A healthy economic region is in everyone's best interest. Businesses are not anti-people, anti-retirees, and economic infrastructure development is not "corporate welfare". Create infrastructure support structures, not dependency. Remove barriers. Information is global: money moves, people move. If the entire community does not act efficiently in unison, then money will go to other regions who do think and act with a global awareness. Enforce strict Global Intellectual Property Rights. Standardize Patent Rights internationally. Develop effective financial strategies - for research, universities, and industries, and their effective partnership. Distant learning infrastructure, and video teleconferencing will favorably impact all the stakeholders; students, people, legislators, businesses, etc. New tools for the visually, and hearing challenged people will open up a underutilized manpower resource.

\subsection{The challenge for the students.}

For the students my biggest challenge to you is to self-indulge yourself with all the different aspects of learning. Enjoy studying, embrace failing intelligently. That means to take creative chances and learn if you are not successful. We need thinkers, not just doers. Learn more than just one narrow specialty, learn that it can take you, and will take you, far beyond the direction you imagine today. Work! Be spontaneously creative. Don't just be a taker of assignments from "the management", suggest new ideas, new projects, new solutions outside your current project. It is a conditioning process, dream creatively and you will be a creator. Learn teamwork skills. Learn more than an optics education. Learn more than to get a job, learn to make jobs, be an entrepreneur! Be one even if you elect to work in a multi-national giant corporation. They will reward you for it.

\subsection{The challenge for the all of us}

The challenge for each of us is to pro-actively work together towards our common goal. We share the concept of a common goal already. Each may have pieces that are not in common with the rest, but there is a common subset. Even if we each do our chosen part we still need a coordinated effort between the industries, the academic, the financial, the political communities. We all need to have our attitudes refocused and their field of regard increased.

In some countries we need to create industries that will create industries, some place for their graduates to go other than into teaching (unless they want to. We clearly need teachers also).

We all need to market the idea, and frequently. Go out and sell it. Create a global awareness of the market size of the industry and its future size, so that investors will put more money into the technology, and governments will support Research and Development and education. Educate our communities that we are not just eye glasses and telescopes Educate our teachers, and legislators at all levels. 
As a group we need to collect data for initial analysis for directional purposes. We need to better identify the stake holders, the who of the vital cycle: Everyone who profits from optics. Some of them are:

The obvious optics community; student, professors, administrators, businesses, societies.

Editors

Publishers

Advertisers

Lawyers

Public sector top to bottom

Public and private schools

Printers

Markets analysts, and their corporations

We need to start. I foresee a staged approach. We need to start with a couple of good first initiatives, doable but on an aggressive schedule, with very frequent meetings. Industry is not all that patient. What about resources? Who is going to pay for all this? I have no doubt that we all will, plan or no plan. If we plan it together, the government (our taxes) will pay less and so will industry. There will be a lot less wasted training, studying, money, and time. In a planned approach each sector will pay their own way, to some degree, for clearly specified expected benefits. Government research and educational grants will take on a new direction. Governments will partner with industry and work for a consortium of industries, industry Clusters. Government grants will match the private sector consortium interest and concentrate on infrastructure building, and less on direct grants to individual corporations. There will need to be lots of sweat equity, shared responsibilities and coordinated actions. Groups will still need to research projects, mildly. We have all seen enough thick tomes of documentation which had no follow-through. We need to prioritize some initiatives, and then do them. The challenge is not just at our doorstep. IT IS IN OUR HOUSE ALREADY! We need long-term solutions. And we need them right now! We need Vision and Champions.

\subsection{Role of an Executive Committee}

- Leadership

- Encourage/Stimulate Involvement

- Provide Continuity

- Supervision

- Support Entrepreneurship

- Personal Commitment

\section{We need to solve our current distribution problem.}

While I believe most of us will acknowledge the shortage of optically trained people in the United States right now, that there are hundreds of millions of dollars worth of contracts that go begging for lack of engineers to perform the work. We are burning out our engineers in general with $50+$ average hour workweeks for engineers, and we have dual parents in the workforce. The decline of the quality of the family structure has been correlated with this over commitment. On the other hand, there is an under-utilization of the very well-trained optics people in France, Germany, Eastern Europe, and Russia, the US has just recently closed its boarders to immigration, and/or there are restrictions on their utilization in too many cases.

\section{Conclusions, Results Expected, Benefits What do "I" get out of it? What are "my" immediate benefits?}

Having dealt with many industry "driven" initiatives I have become accustomed to the justifiable wail "I want my money, my return on investment, soon! Well we can plan it so there is some return "now" but we don't want to lose focus that this is more of a plan for the 21 st Century.

Industry you will get: 


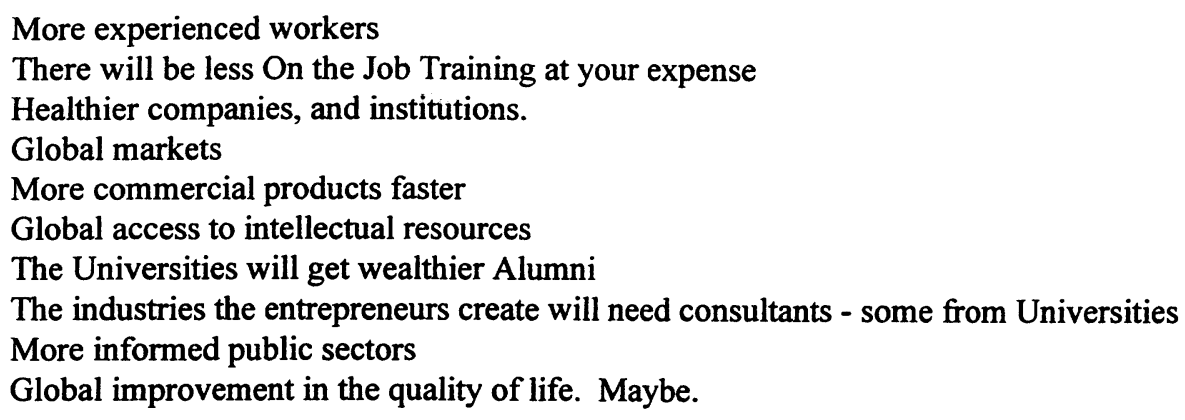

\section{For the skeptics}

I have an even more ambitious plan for "us"!

At the "Education in Optics" conference in Delft, I wanted to put aside the idea that this was too grandiose a plan to accomplish. I suggested that all the conference attendees go to the beach with me to stop the tide from coming in. We couldn't do it. Not today. But the Dutch have done just that and are famous for it. But it took an effort on everyone's part, in many senses of the word. No one institution, no one sector of the Vital Cycle could solve this problem alone. But I believe that all of us could successfully do it together if we wanted to, and its only going to be a matter of time before we will want to do it out of desperate need.

\section{References}

C. Handy, THE Age OF UNREASON, Harvard Business School Press, 1989 